\title{
Use of Dopants for Thoria Sintering Temperature Reduction-Characterization of $\mathrm{THO}_{2}$
}

\author{
Hidetoshi Takiishi ${ }^{1}$, Luis A. Gênova ${ }^{1}$, Elton D. Cavalheira ${ }^{1}$, Marycel B. Cotrim ${ }^{2}$, Wilson Santos $^{2}$ and Paulo E. O. \\ Lainetti $^{2}$ \\ 1. Science and Materials Technology Center-CCTM, Nuclear and Energetic Research Institute (IPEN-CNEN/SP), Av. Prof. Lineu \\ Prestes 2242, São Paulo/SP. CEP 05508-000, Brazil \\ 2. Chemistry and Environment Center-CQMA, Nuclear and Energetic Research Institute (IPEN-CNEN/SP), Av. Prof. Lineu Prestes \\ 2242, São Paulo/SP. CEP 05508-000, Brazil
}

Received: May 17, 2016 / Accepted: June 02, 2016 / Published: December 31, 2016.

\begin{abstract}
Thorium is nearly three times more abundant than uranium in the Earth's crust. Some papers evaluate the thorium resources in Brazil over 1,200,000 metric t. These figures mean that the country is probably the biggest thorium resource in the world, with only part of the territory prospected. Nevertheless, Brazil has not a research program for use of thorium in nuclear reactors, even having dedicated special attention to the subject in the beginning of its nuclear activities, in the fifties and sixties. From 1985 until 2003 IPEN operated a pilot plant for thorium nitrate production and purification, used by Brazilian industry for production of gas mantles. This facility produced over 170 metric $t$ of thorium nitrate. Despite the non-nuclear application, the pilot plant was unique in the southern hemisphere. On the other hand, Brazil has the biggest world niobium resources. The Brazilian thorium and niobium resources added to the predictable future importance of alternative fissile materials have motivated this research, since uranium is a finite resource if used in the present thermal nuclear reactors. Besides this, thorium oxide is an important nuclear reactor material. It is a refractory oxide and its ceramic fabrication process involves a very high temperature sintering treatment considering that thoria melting point is very high $(3,650 \mathrm{~K})$. Cations of elements of the group $\mathrm{VB}(\mathrm{V}, \mathrm{Nb}$ and $\mathrm{Ta})$ have a known effect in the reduction of thoria sintering temperature. IPEN has initiated an investigation about the use of niobium as a dopant for thoria sintering temperature reduction. The thoria used in the research was produced in the IPEN's pilot plant and different amounts of niobium oxide $\left(\mathrm{Nb}_{2} \mathrm{O}_{5}\right)$ will be added to thoria by different routes. The powders will be compressed and the compacted pellets will be sintered at different temperatures. The influence of the different parameters in the density of sintered pellets is being investigated. This paper presents the chemical and physical characterization for the thoria used in the investigation.
\end{abstract}

Key words: Thorium, processing, purification, thoria, dopants, sintering, temperature, reduction.

\section{Introduction}

Although the thorium does not present significant commercial value, in a not too distant future it will probably be an important commodity. Despite some advantages over uranium for use in nuclear reactors, in the almost two centuries since its discovery, the use of thorium was restricted to use for gas mantles, especially in the early twentieth century. Unfortunately,

Corresponding author: Paulo E. O. Lainetti, Ph.D., professor, metallurgist engineer, research fields: waste decomposition in molten salts, nuclear fuel cycle, thorium processing. contrarily to what is happening in some countries in recent years, Brazil is paying little attention to the thorium, even less than in the past, despite its huge reserves. The reasonably assured Brazilian thorium reserves and the estimated additional resources can reach 1.3 million metric tons of $\mathrm{ThO}_{2}$ [1].

Considering nuclear energy as an option, uranium is a finite resource if used in a thermal reactor instead of a breeder. The worldwide uranium reserves could last for more than 50-80 years, depending on the amount of reactors in operation in the next future. With thorium and breeding of ${ }^{233} \mathrm{U}$ in a reactor operating in the 
thermal spectrum this problem can be overcome.

Therefore, Brazil should be involved in this research because energy resources from oil, coal or hydroelectric will last for some decades, a relatively short period of time. Besides this, Brazil has very important thorium resources and this should be considered to establish national priorities. Unfortunately, Brazil has not a thorium program. There are only limited and localized initiatives from some researchers. Some proposals would be an excellent opportunity to keep the existent capabilities in the institution that will be strategically important for the country in the future.

\section{Brief History of Thorium Research Activities at IPEN-CNEN/SP}

Brazil has a long tradition in the thorium technology, from mining of monazite to the production of thorium with purity suitable for nuclear use and IPEN accumulated since the 60's a wide experience in the purification of thorium, obtained primarily from the monazite processing.

The first reports on the exploitation of monazite in Brazil date back to 1886, when Englishman John Gordon began exporting to the ore from the municipality of Prado, State of Bahia to Europe, for use in incandescent gas lamps, before the advent of electricity from the 1920s [1]. Between the two World Wars, there was a gradual decline in the consumption of monazite. In 1951, the Brazilian government banned the export of concentrates of monazite. DNPM (National Department of Mineral Production) data [2] estimate that from 1886 to 1950 , were exported from Brazil about 95,000 $t$ of monazite concentrate.

Since the sixties, IPEN-CNEN/SP has performed some activities and developments related to the thorium fuel cycle, mainly in purification by solvent extraction. The thorium used in the research activities at IPEN was obtained from concentrates produced as side products of the processing of monazite sands from the State of Espirito Santo. The alkaline process for breaking up the monazite was used in Brazil on an industrial scale from 1948 until the beginning of the 90's years by the company Orquima.

Orquima-Indústrias Químicas Reunidas Company started processing of monazite in Sao Paulo aiming at taking advantage of the rare earths produced, sodium diuranate and rare earth basic carbonate, purchased by the Federal Government and rare earth chlorides for export. In 1949, the chemical processing of monazite, to produce lanthanide chlorides and tri-sodium phosphate, was started at the Santo Amaro mill-USAM (acronym for Usina Santo Amaro-Orquima S/A), located in Sao Paulo, the largest Brazilian city. The city grew rapidly after the fifties, mainly in the neighborhood of the facility, which caused its closure years later.

The first phase of the monazite processing consists of the extraction, washing and drying of monazite bearing sands taken from beaches. Then, physical separation processes separate the four minerals: ilmenite, rutile, monazite and zircon. Owing to public pressure, economic and radiological problems, the chemical processing of monazite stopped in 1992 [3]. The separation factors of thorium from rare earths and phosphates were about almost $100 \%$, and the thorium was obtained in a form very suitable for solvent extraction purification: thorium sulfate, as reported in Ref. [4].

The production and purification of thorium compounds was carried out at IPEN for about 18 years. During this period, the main product sold was the thorium nitrate with high purity (nuclear grade) having been produced over 170 metric tons of this material in this period, obtained through solvent extraction. The main raw material employed during the thorium nitrate production period was the thorium sulfate produced by Orquima. The crystallized thorium sulfate was first transformed in thorium carbonate by addition of water, sodium carbonate and sodium hydroxide. Further, the carbonate was transformed in thorium nitrate by dissolution with nitric acid [5]. To obtain high purity 
thorium nitrate, the most satisfactory process is purification by solvent extraction. This material was produced by the unique thorium purification plant in south hemisphere. This facility has already been partially decommissioned [6].

\section{Thoria Sintering Temperature Reduction}

The Brazilian thorium and niobium resources added to the predictable future importance of alternative fissile materials have motivated this research, since uranium is a finite resource if used in the present thermal nuclear reactors. Besides this, thorium oxide is an important nuclear reactor material. It is a refractory oxide and its ceramic fabrication process involves a very high temperature sintering considering that thoria melting point is very high $(3,650 \mathrm{~K})$. Nevertheless, cations of elements of the group $\mathrm{VB}(\mathrm{V}, \mathrm{Nb}$ and $\mathrm{Ta})$ have a known effect in the reduction of thoria sintering temperature [7].

Taking into account the importance of keeping the IPEN's capability and tradition in the thorium compounds processing, the CQMA-Chemistry and Environment Center and CCTM-Science and Materials Technology Center, both centers of IPEN, have initiated a cooperation to investigate the use of niobium as a dopant for thoria sintering temperature reduction.

\subsection{Experimental Procedure}

Initially, pure $\mathrm{ThO}_{2}$ pellets were prepared to determine the density that can be reached without the use of any dopant. The thoria used in the research was produced in the IPEN's pilot plants. After the transformation of thorium sulfate into a basic carbonate, a high purity thorium oxide was obtained by calcination at $900-1,000{ }^{\circ} \mathrm{C}$. In a second phase of this development different amounts of niobium oxide $\left(\mathrm{Nb}_{2} \mathrm{O}_{5}\right)$ supplied by CBMM (Companhia Brasileira de Metalurgia e Mineração) will be added to thoria by different routes to determine the reduction in the sintering temperature.
Three different $\mathrm{ThO}_{2}$ powders were selected and analyzed by WDXRF (wavelength dispersive spectrometry X-ray fluorescence). The results are presented in Table 1. In accordance with information of the niobium oxide supplier, the chemical composition of the compound is $>99.8 \%$ in mass of $\mathrm{Nb}_{2} \mathrm{O}_{5}$.

Since Sample 3 was the purest, it was selected for the analysis by ICP-OES (inductively coupled plasma/optical emission spectrometry) in the equipment ICP-OES Spectro, model ARCOS of the CQMA of IPEN. For the analysis, the $\mathrm{ThO}_{2}$ powder was attacked by $\mathrm{HNO}_{3}+\mathrm{HF}$ acid solution. The results are summarized in Table 2.

The average particle size of the $\mathrm{Nb}_{2} \mathrm{O}_{5}$ and the 3 samples of the $\mathrm{ThO}_{2}$ were determined by the Fisher method. Results are given in Table 3.

Table 1 Analysis of 3 different $\mathrm{ThO}_{2}$ powders by WDXRF.

\begin{tabular}{llll}
\hline $\begin{array}{l}\text { Compound/ } \\
\text { element }\end{array}$ & $\begin{array}{l}\mathrm{ThO}_{2} \text { Sample 1 } \\
\text { (Mass \%) }\end{array}$ & $\begin{array}{l}\mathrm{ThO}_{2} \text { Sample 2 } \\
\text { (Mass \%) }\end{array}$ & $\begin{array}{l}\mathrm{ThO}_{2} \text { Sample 3 } \\
\text { (Mass \%) }\end{array}$ \\
\hline $\mathrm{ThO}_{2}$ & $99.49 \pm 0.05$ & $99.94 \pm 0.05$ & $99.97 \pm 0.05$ \\
$\mathrm{Na}$ & $0.46 \pm 0.05$ & $0.04 \pm 0.02$ & $0.03 \pm 0.02$ \\
$\mathrm{Cl}$ & $0.05 \pm 0.02$ & $0.02 \pm 0.01$ & $<0.01$ \\
$\mathrm{P}$ & $0.012 \pm 0.005$ & $0.003 \pm 0.002$ & $<0.002$ \\
\hline
\end{tabular}

Table 2 Main impurities present in the $\mathrm{ThO}_{2}$ powder-Sample 3 analyzed by ICP-OES.

\begin{tabular}{ll}
\hline Element & $\begin{array}{l}\mathrm{ThO}_{2} \\
\left(\mu \mathrm{g} \cdot \mathrm{g}^{-1}\right)\end{array}$ \\
\hline $\mathrm{K}$ & $12 \pm 3$ \\
$\mathrm{Ca}$ & $270 \pm 35$ \\
$\mathrm{Mg}$ & $65 \pm 8$ \\
$\mathrm{Sr}$ & $<30$ \\
$\mathrm{Fe}$ & $350 \pm 15$ \\
$\mathrm{Cu}$ & $5 \pm 1$ \\
$\mathrm{Ni}$ & $25 \pm 8$ \\
$\mathrm{Zn}$ & $12 \pm 4$ \\
$\mathrm{Co}$ & $4 \pm 1$ \\
$\mathrm{Cd}$ & $0.9 \pm 0.1$ \\
$\mathrm{Mn}$ & $5 \pm 1$ \\
\hline
\end{tabular}

Table 3 Average particle size of the $\mathrm{Nb}_{2} \mathrm{O}_{5}$ and $\mathrm{ThO}_{2}$ powders by Fisher method.

\begin{tabular}{llll}
\hline \multicolumn{4}{l}{ Average diameter $(\mu \mathrm{m})$} \\
\hline $\mathrm{Nb}_{2} \mathrm{O}_{5}$ & $\mathrm{ThO}_{2}$ & & \\
\hline & Sample 1 & Sample 2 & Sample 3 \\
$1.9 \pm 0.1$ & $0.7 \pm 0.1$ & $0.7 \pm 0.1$ & $0.7 \pm 0.1$ \\
\hline
\end{tabular}



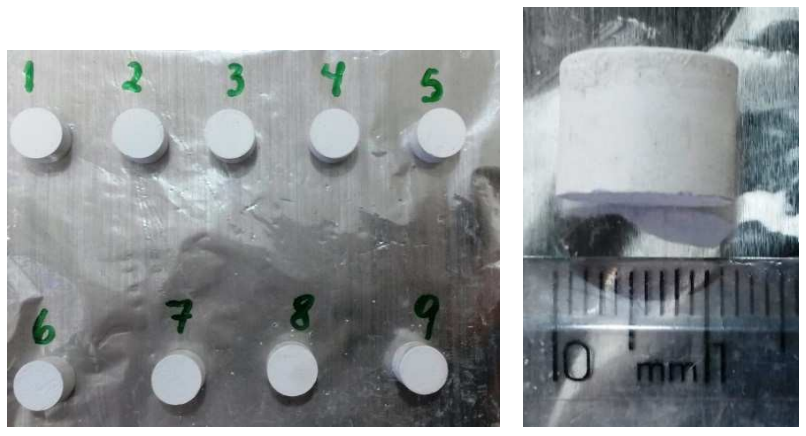

Fig. 1 Uniaxial compacted pellets with pure $\mathrm{ThO}_{2}$ powder.

Since $\mathrm{ThO}_{2}$ powder from Sample 3 was the purest, it was selected for the subsequent procedures. The powder was dried at $90{ }^{\circ} \mathrm{C}$ by 24 hours. Nine previously weighted amounts of pure $\mathrm{ThO}_{2}$ powder Sample 3 were compacted in a hydraulic press using a steel die with $12 \mathrm{~mm}$ diameter. The pellets prepared for the isostatic compression can be observed in Fig. 1.

The nine uniaxial compacted pellets were then isostatic pressed, as can be observed in Fig. 2. The pellet calculated geometric density results for the nine pellets are presented in Table 4.

The $\mathrm{ThO}_{2}$ pellets (without using additives by now) were sintered in atmospheric ambient air at $1,600{ }^{\circ} \mathrm{C}$ for periods of one, three and five hours. It was used a resistive electric furnace produced by Lindberg. After sintering were evaluated the dimensional reductions in the high and diameter. The results are presented in Table 5 .
The sintered pellet geometric densities were calculated using the average dimensions and the results are presented in Table 6 . The theoretical density of $\mathrm{ThO}_{2}$ is assumed here as $10.00 \mathrm{~g} / \mathrm{cm}^{3}$ at $298 \mathrm{~K}$.

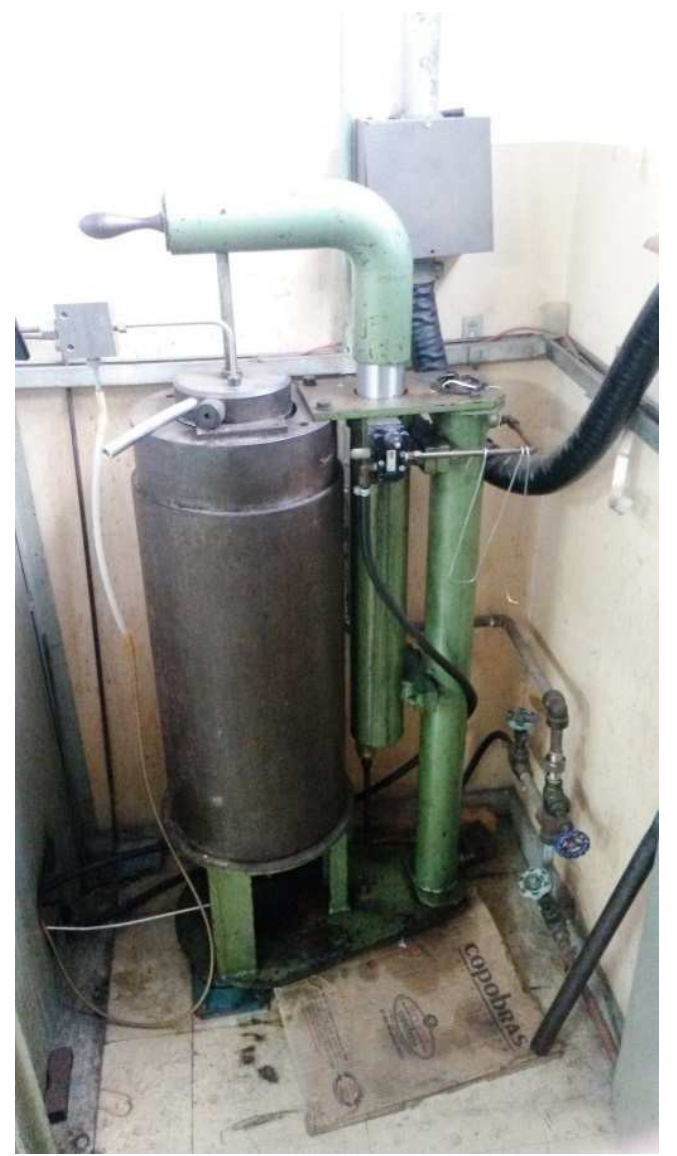

Fig. 2 Isostatic press machine used for pressing of pre-compacted $\mathrm{ThO}_{2}$ pellets.

Table 4 Green pellet calculated geometric density.

\begin{tabular}{|c|c|c|c|c|c|c|c|c|c|c|c|}
\hline & & & & & & Pellet & ometric & density & & & \\
\hline Pellet & Mass (g & & & ight (1 & & & & neter $(\mathrm{n}$ & & $\begin{array}{l}\text { Average } \\
\text { volume }\end{array}$ & Average \\
\hline & & & & & $\begin{array}{l}\text { Average } \\
\text { height }\end{array}$ & & & & $\begin{array}{l}\text { Average } \\
\text { diameter }\end{array}$ & & \\
\hline 1 & 4.943 & 7.60 & 7.60 & 7.65 & 7.62 & 11.85 & 11.90 & 11.90 & 11.88 & 845 & 5.8514 \\
\hline 2 & 4.985 & 7.70 & 7.70 & 7.70 & 7.70 & 11.90 & 11.85 & 11.85 & 11.87 & 852 & 5.8537 \\
\hline 3 & 4.994 & 7.65 & 7.70 & 7.65 & 7.67 & 11.85 & 11.85 & 11.90 & 11.87 & 848 & 5.8897 \\
\hline 4 & 4.905 & 7.60 & 7.60 & 7.65 & 7.62 & 11.90 & 11.85 & 11.90 & 11.88 & 845 & 5.8064 \\
\hline 5 & 4.963 & 7.60 & 7.65 & 7.65 & 7.63 & 11.90 & 11.85 & 11.90 & 11.88 & 847 & 5.8622 \\
\hline 6 & 4.950 & 8.60 & 8.50 & 8.50 & 8.53 & 11.40 & 11.40 & 11.40 & 11.40 & 871 & 5.6831 \\
\hline 7 & 4.903 & 8.30 & 8.30 & 8.25 & 8.28 & 11.50 & 11.50 & 11.55 & 11.52 & 863 & 5.6822 \\
\hline 8 & 4.944 & 7.70 & 7.65 & 7.65 & 7.67 & 11.90 & 11.95 & 11.95 & 11.93 & 857 & 5.7658 \\
\hline 9 & 4.912 & 8.70 & 8.75 & 8.75 & 8.73 & 11.20 & 11.25 & 11.25 & 11.23 & 866 & 5.6751 \\
\hline
\end{tabular}


Table 5 Shrinkage of the $\mathrm{ThO}_{2}$ pellets after sintering.

\begin{tabular}{|c|c|c|c|c|c|c|c|c|c|c|c|c|c|}
\hline \multirow{2}{*}{$\begin{array}{l}\text { Sintering } \\
\text { time at } \\
1,600^{\circ} \mathrm{C}\end{array}$} & \multirow{2}{*}{ Pellet } & \multicolumn{6}{|c|}{ Height after sintering $(\mathrm{mm})$} & \multicolumn{6}{|c|}{ Diameter after sintering $(\mathrm{mm})$} \\
\hline & & & & & Aver age & $\begin{array}{l}\text { Shrink } \\
\text { age }\end{array}$ & $\%$ & & & & Aver age & $\begin{array}{l}\text { Shrink } \\
\text { age }\end{array}$ & $\%$ \\
\hline \multirow{3}{*}{$1 \mathrm{~h}$} & 1 & 6.95 & 6.95 & 6.90 & 6.93 & 0.68 & 8.97 & 10.85 & 10.80 & 10.80 & 10.82 & 1.07 & 8.98 \\
\hline & 2 & 7.15 & 7.10 & 7.15 & 7.13 & 0.57 & 7.36 & 10.90 & 10.80 & 10.80 & 10.83 & 1.03 & 8.71 \\
\hline & 3 & 7.10 & 7.10 & 7.10 & 7.10 & 0.57 & 7.39 & 10.90 & 10.80 & 10.80 & 10.83 & 1.03 & 8.71 \\
\hline \multirow{3}{*}{$3 \mathrm{~h}$} & 4 & 6.70 & 6.75 & 6.77 & 6.74 & 0.88 & 11.51 & 10.60 & 10.55 & 10.60 & 10.58 & 1.30 & 10.94 \\
\hline & 5 & 6.80 & 6.75 & 6.75 & 6.77 & 0.87 & 11.35 & 10.60 & 10.55 & 10.60 & 10.58 & 1.30 & 10.94 \\
\hline & 6 & 7.60 & 7.60 & 7.60 & 7.60 & 0.93 & 10.94 & 10.20 & 10.15 & 10.15 & 10.17 & 1.23 & 10.82 \\
\hline \multirow{3}{*}{$5 \mathrm{~h}$} & 7 & 7.20 & 7.15 & 7.15 & 7.17 & 1.12 & 13.48 & 10.10 & 10.10 & 10.15 & 10.12 & 1.40 & 12.16 \\
\hline & 8 & 6.75 & 6.75 & 6.75 & 6.75 & 0.92 & 11.96 & 10.50 & 10.50 & 10.45 & 10.48 & 1.45 & 12.15 \\
\hline & 9 & 7.60 & 7.65 & 7.60 & 7.62 & 1.12 & 12.79 & 9.90 & 9.90 & 9.90 & 9.90 & 1.33 & 11.87 \\
\hline
\end{tabular}

Table 6 Sintered average geometric density of $\mathrm{ThO}_{2}$ pellets.

\begin{tabular}{llllll}
\hline Pellet & Mass $(\mathrm{g})$ & $\begin{array}{l}\text { Sintered average } \\
\text { height }(\mathrm{mm})\end{array}$ & $\begin{array}{l}\text { Sintered average } \\
\text { diameter }(\mathrm{mm})\end{array}$ & $\begin{array}{l}\text { Sintered average geometric } \\
\text { density }\left(\mathrm{g} / \mathrm{cm}^{3}\right)\end{array}$ & $\begin{array}{l}\text { \% Related to ThO } \mathrm{T}_{2} \text { theoretical } \\
\text { specific mass }\end{array}$ \\
\hline 1 & 4.943 & 6.93 & 10.82 & 7.757 & 77.57 \\
2 & 4.985 & 7.13 & 10.83 & 7.590 & 75.90 \\
3 & 4.994 & 7.10 & 10.83 & 7.636 & 76.36 \\
4 & 4.905 & 6.74 & 10.58 & 8.278 & 82.78 \\
5 & 4.963 & 6.77 & 10.58 & 8.339 & 83.39 \\
6 & 4.950 & 7.60 & 10.17 & 8.018 & 80.18 \\
7 & 4.903 & 7.17 & 10.12 & 8.501 & 85.01 \\
8 & 4.944 & 6.75 & 10.48 & 8.491 & 84.91 \\
9 & 4.912 & 7.62 & 9.90 & 8.374 & 83.74 \\
\hline
\end{tabular}

\section{Conclusions}

In accordance with the literature, the densification kinetics of thoria can be effectively controlled via suitable defect density modifications. One method of achieving faster densification has been the use of small amounts of metal oxides as additives. Several dopants such as $\mathrm{CaO}, \mathrm{SrO}, \mathrm{Fe}_{2} \mathrm{O}_{3}, \mathrm{ZnO}$, etc. are known to produce an enhancement of density. However, the mechanism by which various dopants affect the defect structure of thoria to allow this rapid mass-transport is not well understood.

Kutty et al. [7] concluded that for $\mathrm{ThO}_{2}-0.25 \%$ $\mathrm{Nb}_{2} \mathrm{O}_{5}$, the combination of higher valence additive and oxidizing atmosphere led to a higher defect concentration leading to higher density and larger grain size. The data obtained by Ananthasivan et al. [8] indicate that thoria doped with $0.1,0.25$ and $0.50 \mathrm{~mol} \%$ niobia could be sintered to a density of $9.5 \mathrm{Mg} / \mathrm{m}^{3}$ at $1,523,1,523$ and $1,423 \mathrm{~K}$, respectively, using
$\mathrm{ThO}_{2}-\mathrm{Nb}_{2} \mathrm{O}_{5}$ powders obtained by using the gel-combustion procedure.

The present study is still in a preliminary stage and with limited data. Therefore, it is not possible any conclusion about the prevailing sintering mechanisms. In the first phase of this work different $\mathrm{ThO}_{2}$ powders were prepared and chemically characterized. The purest material was selected and green pellets were prepared using initially uniaxial compression in a hydraulic press machine followed by isostatic compression. The green geometric densities were calculated. The pellets were sintered for periods of 1,3 and 5 hours in atmospheric ambient air at $1,600{ }^{\circ} \mathrm{C}$. The sintered geometric densities were calculated. For the conditions mentioned above, it was possible to reach a maximum geometric density of about $8.5 \mathrm{~g} / \mathrm{cm}^{3}$ (or $85 \%$ the theoretical density) with pure $\mathrm{ThO}_{2}$, i.e. without the use of dopants.

In a second phase of this work, different amounts of $\mathrm{Nb}_{2} \mathrm{O}_{5}$ will be added to the $\mathrm{ThO}_{2}$ powder by different 
routes. Then, the pellets preparation procedure will be repeated. The pellets will be sintered at different temperatures and times. Finally, the geometric and hydrostatic densities of the sintered pellets and the reduction in the sintering temperature to achieve similar densities will be evaluated.

\section{References}

[1] Gentile, E., and Filho, P. M. F. 1996. Minerais Radioativos-Projeto Diagnóstico. Brazilian association of metallurgy and materials report, São Paulo, in Portuguese.

[2] Lauria, D. C., and Rochedo, E. R. R. 2005. "The Legacy of Monazite Processing in Brazil." Radiation Protection Dosimetry 114 (4): 546-50.

[3] Paschoa, A. S. 1998. "Potential Environmental and Regulatory Implications of NORM.” Applied Radiation Isotopes 49 (3): 189-96.
[4] Bril, K. J., and Krumholz, P. 1965. Produção de Óxidos de Tório Nuclearmente Puros. IEA-PUB-00115, Atomic energy institute report, São Paulo, in Portuguese.

[5] Lainetti, P.E. O., Freitas, A. A., and Mindrisz, A. C. 2014. "Review of Brazilian Activities Related to the Thorium Fuel Cycle and Production of Thorium Compounds at IPEN-CNEN/SP." Journal of Energy and Power Engineering 8 (12): 1983-90.

[6] Lainetti, P. E. O. 2007. "Decommissioning of Nuclear Fuel Cycle Facilities in the IPEN-CNEN/SP." In Proceedings of the European Nuclear Conference, 110-4.

[7] Kutty, T. R. G., Khan, K. B., Kumar, A., and Kamath, H. S. 2009. "Densification Strain Rate in Sintering of $\mathrm{ThO}_{2}$ and $\mathrm{ThO}_{2}-0.25 \% \mathrm{Nb}_{2} \mathrm{O}_{5}$ Pellets." Science of Sintering 41 (2): 103-15.

[8] Ananthasivan, K., Anthonysamy, S., Sudha, C., Terrance, A. L. E., and Vasudeva Rao, P. R. 2002. "Thoria Doped with Cations of Group VB-Synthesis and Sintering." Journal of Nuclear Materials 300 (2): 217-29. 